\title{
Revisitando el pasado industrial argentino. Los debates sobre estrategias de desarrollo en el Programa Conjunto para el Desarrollo Agropecuario e Industrial (1962-1965)*
}

\author{
- RAmiro Coviello \\ - Marcelo Rougier \\ Instituto Interdisciplinario de Economía Política de Buenos Aires \\ Universidad de Buenos Aires, Facultad de Ciencias Económicas \\ Consejo Nacional de Investigaciones Científicas y Técnicas
}

\section{Introducción}

La oleada neoliberal que inundó Latinoamérica durante el último cuarto del siglo XX consagró la revisión neoclásica acerca del período conocido como «industrialización impulsada por el Estado», ${ }^{1}$ que se había extendido en la región entre inicios de la década de 1930 y mediados de la de 1970. Preocupada principalmente por la inestabilidad macroeconómica característica de la etapa previa, dicha visión cuestionó de plano el desarrollo manufacturero y la ampliación de la intervención estatal que lo había acompañado. ${ }^{2}$ El triunfo que experimentó en los años noventa esa «leyenda negra» de la «industrialización por sustitución de importaciones» latinoamericana se configuró alrededor de tres señalamientos asociados - la ineficiencia del sector manufacturero, su escasa competitividad internacional y, como contracara, su excesivo mercadointernismo-, ante los cuales enalteció un contraejemplo simétrico: el éxito de la industrialización guiada por exportaciones de los new industrializaded countries del este asiático. ${ }^{3}$ Empero, el fracaso socio-económico que

* Una versión preliminar fue presentada en las XXVI Jornadas de la Asociación Argentina de Historia Económica, 19-21 de septiembre, Universidad Nacional de La Pampa, Santa Rosa.

1. Thorp (1998).

2. El volumen editado por Dornbusch y Edwards (1992) es ejemplo de ello.

3. Así, se descartaron los matices que en el decenio anterior habían sido introducidos por trabajos orientados a promover una «nueva industrialización» que, no casualmente, fueron muy críticos de la pretensión neoclásica de hacer del caso de los países asiáticos un «paradigma». Véase Fajnzylber (1983).

Fecha de recepción: diciembre 2018

Versión definitiva: mayo 2019

Revista de Historia Industrial

N. ${ }^{o}$ 76. Año XXVIII. 2019 
evidenciaron las políticas neoliberales hacia el cambio de siglo motivó abordajes que han complejizado las visiones sobre el pasado industrial y que han contribuido, desde nuevos relevamientos empíricos, a cuestionar las consideraciones reduccionistas que sobre el sector habían brindado las interpretaciones neoclásicas. ${ }^{4}$

En el caso argentino, fue la crisis de 2001-2002 el disparador que permitió combinar la revitalización del interés por los actores (contracara del debilitamiento de los paradigmas estructuralistas) con una revaloración positiva de la industrialización y de la intervención estatal. Los debates sobre el impacto social de la desindustrialización selectiva ofrecieron un marco propicio para rediscutir el lugar de la industria en la economía y en la sociedad argentinas y el rol de los empresarios, del Estado y de las políticas públicas en el desarrollo. Así, por ejemplo, la literatura sobre planificación abandonó una mirada centrada primordialmente en señalar sus déficits para adoptar otra que subraya los significativos aportes generados por el desarrollo institucional de los organismos de planeamiento a la formación de cuadros técnico-burocráticos y tecnologías de gobierno. ${ }^{5}$ Por su parte, los estudios interesados en el pensamiento industrial, aspecto generalmente descuidado en la historiografía latinoamericana, han identificado en el caso argentino la existencia de intensos debates sobre estrategias de desarrollo, protagonizados en los años sesenta por los noveles expertos en economía, quienes formularon fuertes críticas al sendero sustitutivo-mercadointernista y promovieron alternativas industrial-exportadoras. ${ }^{6}$ La exhumación de esas controversias contrasta con las visiones neoclásicas, que las habían soterrado mediante la homologación entre industrialismo y orientación «autarquizante».

En diálogo con esas líneas de renovación sobre el pasado industrial argentino, este trabajo se propone estudiar el caso del Programa Conjunto para el Desarrollo Agropecuario e Industrial (1962-1965), impulsado por el Consejo Federal de Inversiones (CFI) — organismo ligado a la planificación cuya creación coincide con la expansión del Estado «desarrollista»- y por la Confederación General Económica (CGE) —entidad patronal instituida en 1952 alrededor de los intereses de la burguesía nacional-. Específicamente, se pretende analizar el vínculo entre dicha iniciativa y las problematizaciones que hacia fines de los años cincuenta comenzaron a configurarse alrededor de los debates acaecidos en distintos ámbitos expertos en conformación, poniendo

4. Véase una revisión de esta literatura en Rougier (2016).

5. Berrotarán (2003); Fiszbein (2010); Grondona (2014); Jáuregui (2014). En un balance de ámbito regional Thorp (1998) destaca que, allende el éxito o fracaso en la implementación de programas, el despliegue del planeamiento impulsó la formación de recursos humanos, la recopilación de datos y los intentos de conocer y comprender la realidad nacional, en íntima asociación con proyectos de reforma.

6. Rougier y Odisio (2017). 
el foco en la emergencia de propuestas de reorientación del sendero de industrialización argentino en un sentido exportador y en el modo en que estas anudaron la cuestión con la preocupación del estrangulamiento externo, en tanto articulador de las controversias económicas del período. ${ }^{7}$ La relevancia de revisitar esas discusiones se justifica porque, como se verá en los dos apartados que siguen a esta introducción, durante los años sesenta, el modelo de desarrollo de Argentina comenzó a desplazarse en una dirección afín a la que indicaba el saldo de las polémicas en cuestión. Luego, puede argüirse que el análisis de las mismas abona a una mejor y más cabal comprensión de dicho desplazamiento.

Para cumplir con los objetivos apuntados, el artículo abreva, por un lado, en la historia del pensamiento industrial, presentando las distintas aristas de los debates que dieron vida a las mentadas problematizaciones. Por el otro, se interesa por el papel que desempeñaron dos actores específicos de distinta índole - un organismo público (el CFI) y una entidad corporativa empresaria (CGE) - en la configuración de esas discusiones, en tanto oficiaron, como se verá, como ámbitos propicios para su institucionalización. Esto último resulta significativo porque, especialmente en el caso de los organismos públicos (aunque no solo), dicha institucionalización ha tendido a motorizar ensayos de traducción del saldo de esos debates en el diseño de políticas económicas. ${ }^{8}$

En vistas de ello, primero se describen las transformaciones estructurales que comenzaron a producirse en la economía argentina a partir de la crisis de 1962-1963 y los debates sobre estrategias de desarrollo que las acompasaron. Luego, se caracterizan las instituciones impulsoras del Programa y los rasgos generales del mismo. En tercer lugar, se presenta el análisis documental sobre la iniciativa en cuestión, focalizando en los aportes que abordan la estrategia de desarrollo en general y/o el sector externo. Estos se organizan en dos subconjuntos, según el modo en que aparecen articuladas sus propuestas y su relación con los debates que les fueron contemporáneos. Finalmente, se sistematizan las conclusiones alcanzadas.

7. Foucault (2003) define problematización como un trabajo de reflexión que articula una preocupación fundamental (el estrangulamiento externo) en una cuestión: ¿Con qué estrategia de industrialización resolverlo?

8. Aunque este señalamiento es central para resaltar la importancia de la institucionalización de las controversias estudiadas, cabe advertir al lector que el análisis del modo en que los debates que aquí se presentan fueron traducidos en la implementación de políticas públicas excede a los objetivos de este trabajo. Empero, hay que dejar asentado que estudios como el de Mallon y Sourrouille (1973) muestran que, en la Argentina de los años sesenta, se implementaron políticas económicas favorables a la exportación de manufacturas. 


\section{Una coyuntura de cambio}

Hacia 1962, se desató una aguda crisis en el sector externo que, gracias al ajuste implemento por el gobierno de José Guido (1962-1963), se propagó velozmente al resto de la economía argentina, afectando en especial al sector manufacturero. ${ }^{9}$ Aunque esa depresión no escapó a la dinámica cíclica del stop and go, que gobernó la economía nacional durante el tercer cuarto del siglo XX, adquirió un significado particular, pues exhibió los límites de la respuesta ensayada ante los sucesivos estrangulamientos externos que habían obstaculizado el proceso de desarrollo desde la crisis de 1949-1952. Esto fue reforzado políticamente por el derrocamiento del gobierno de Arturo Frondizi (1958-1962), que había profundizado esa respuesta. Inaugurada por el peronismo, esta apuntaba a reducir el coeficiente de importaciones al mínimo posible, siendo la autarquía su límite hipotético. Para ello, procuraba que la industrialización sustitutiva avanzara sobre las ramas básicas y pesadas.

A nivel estructural, la crisis de 1962-1963 condujo el proceso de desarrollo argentino hacia una nueva etapa, en la que las exportaciones industriales comenzarían a ganar relevancia para el sector externo. ${ }^{10}$ Algunos autores relacionan esta «industrialización expansiva de exportaciones» con la creación de la Asociación Latinoamericana de Libre Comercio (ALALC) en 1960 y con la implementación de medidas gubernamentales relativas a ello. ${ }^{11}$ Debe sumarse el lugar que adquirió en la agenda internacional el incremento de las exportaciones manufactureras de los países «en desarrollo», especialmente tras la conformación en 1964 de la organización de la Conferencia de las Naciones Unidas para el Comercio y el Desarrollo (UNCTAD, por sus siglas en inglés), cuya Secretaría General quedó a cargo de Raúl Prebisch, quien venía de conducir la Comisión Económica para América Latina (CEPAL). Otros autores explican el despegue de las exportaciones manufactureras argentinas por la actitud adoptada por las empresas fabriles más modernas, que «descubrieron» en el mercado externo una salida para los excedentes generados por la contracción del consumo doméstico. No es objeto de este trabajo determinar cuál de esas causas primó. Basta aquí reconocer que el ascenso que experimentaron las ventas externas manufactureras y su combinación con la continuación del proceso sustitutivo permiten afirmar

9. La utilización de la capacidad industrial instalada cayó por debajo del 55\% (Mallon y Sourrouille, 1973).

10. Con todo, la brecha de divisas de la actividad industrial estuvo lejos de cerrarse y las exportaciones siguieron teniendo escasa incidencia en el crecimiento manufacturero.

11. Fundamentalmente, financiación a la producción de bienes de exportación no tradicionales, exención del pago de impuestos a las ventas, draw-back y reembolso de otros impuestos internos pagados por exportadores (Mallon y Sourrouille, 1973, pp. 130-131). 
que, tras la crisis de 1962-1963, Argentina comenzó a desplazarse hacia un modelo «mixto» de desarrollo. ${ }^{12}$

\section{El desplazamiento de las problematizaciones expertas}

Ese desplazamiento estructural fue acompasado por otro, acaecido al nivel de las problematizaciones expertas, pues, a comienzos de los años sesenta, comenzaron a propagarse las críticas a la estrategia sustitutiva que desde fines de los cincuenta venían formulando los emergentes economistas profesionales. Estas cuestionaban la generalización del proteccionismo, las deformaciones de costos que acarreaba y la orientación mercadointernista de la industrialización. En paralelo, las propuestas de reorientación industrial-exportadora del sendero de desarrollo comenzaron a ganar adeptos, dando lugar a la emergencia y posterior consolidación de un «consenso exportador industrial» (CEI), cuyos principales lineamientos gobernarían las diversas variantes estratégicas ensayadas durante la segunda mitad de los años sesenta y la primera de los setenta. ${ }^{13}$

En mayo de 1963, ese desplazamiento recibió el espaldarazo de Prebisch, quien presentó ante el Décimo Período de Sesiones de la CEPAL, celebrado en Mar del Plata, el trabajo titulado Hacia una dinámica del desarrollo latinoamericano. Allí consagró el «integracionismo» regional, en ascenso dentro del organismo desde fines de los años cincuenta, instalándolo como «continuación y superación» del «cepalismo clásico», que había apelado a la protección arancelaria de la industria y a la instalación de nuevas ramas sustitutivas. ${ }^{14}$ La novedad pasaba por la apuesta a un intercambio más activo de manufacturas, no solo entre países latinoamericanos, sino también con el resto del mundo, pues, de no producirse, las economías de la región serían llevadas «a un tipo de desarrollo cada vez más cerrado»..$^{15}$

Ahora bien, aunque buena parte de los economistas locales se adhirieron al CEI, dentro de sus fronteras se desplegaron variantes heterogéneas. En el período abarcado en este trabajo (1962-1965), que antecede a la consolidación de aquel, estas pueden agruparse alrededor de dos de sus figuras «pioneras». ${ }^{16}$

12. Esta noción ha sido postulada por Ocampo (2004) a escala regional. Aunque no ha sido empleada específicamente para Argentina, existe un amplio consenso acerca de que la mentada crisis cerró la etapa abierta a comienzos de los años cincuenta. Véase Gerchunoff y Llach (1975).

13. Rougier y Odisio (2017).

14. Devés Valdés (2003).

15. Prebisch (1963), pp. 9-10.

16. Rougier y Odisio (2017) datan la consolidación del CEI en 1966, cuando el Centro de Investigaciones Económicas del Instituto Di Tella, ámbito clave para la circulación de los economistas profesionales, acogió la conferencia internacional «Estrategias para el sector ex- 
Aldo Ferrer, doctor en Ciencias Económicas, venía planteando desde fines de los años cincuenta la necesidad de complementar la integración fabril con una diversificación exportadora favorable a los productos industriales, pues mejoraría las condiciones de eficiencia vía el aprovechamiento de economías de escala. Este planteamiento comenzó a desplegarse en el Informe sobre la situación económica, elaborado por el Grupo de Trabajo en Asuntos Económicos (GTAE) del radicalismo intransigente y entregado a Frondizi en abril de 1958. Buena parte de los expertos de ese equipo coordinado por Ferrer, que seguirían ligados a él mediante su posterior incorporación al gabinete económico bonaerense, habían trabajado durante los años previos en el Grupo Conjunto Gobierno Argentino-Naciones Unidas. La labor de ese consorcio de expertos internacionales y locales fue condensada en el informe El desarrollo económico de la Argentina, redactado en la CEPAL ( «Informe CEPAL/Grupo Conjunto») y presentado también en $1958 .{ }^{17}$ En ese trabajo puede hallarse un antecedente del planteamiento en cuestión, aunque allí el fomento de las exportaciones industriales aparece identificado solo como aporte adicional de divisas, manteniéndose desconectado de los obstáculos que presentaba el avance de la integración fabril. Esa conexión, establecida en el trabajo del GTAE, sería articulada con mayor claridad por Ferrer en La economía argentina (1963). Allí, consagró lo que aquí se denomina «argumento de la complementariedad», en tanto variante del CEI que contemplaba la integración manufacturera y la salida fabril al exterior como senderos necesariamente complementarios. ${ }^{18}$

Otra era la visión sostenida desde Panorama de la Economía Argentina, una revista fundada en 1957 por Carlos Moyano Llerena, al calor del proceso de modernización de las Ciencias Económicas. ${ }^{19}$ Allí habían comenzado a esbozarse críticas severas a la industrialización sustitutiva, señalando que su profundización vía las industrias básicas era incompatible con la reorientación exportadora del sector. Según se apuntaba, la única manera de encarar esa senda era mejorando las condiciones de eficiencia y, en consecuencia, la productividad. En esa dirección, y con claras resonancias de los planteamien-

terno y desarrollo económico». Allí se clarificaron el amplio consenso alcanzado y los ejes en debate a su interior.

17. Esta experiencia fue producto de la solicitud de asistencia que, por recomendación de Prebisch, la dictadura de la autodenominada «Revolución Libertadora» (1955-1958) realizó a la ONU, para realizar un estudio integral de la economía argentina (Sikkink, 1988).

18. Posteriormente, Ferrer (1970) bautizaría su propuesta como «modelo industrial integrado y abierto».

19. Este abogado había iniciado un posgrado en Economía en Oxford, que debió interrumpir por el estallido de la Segunda Guerra Mundial. De regreso al país, se integró al grupo de la Revista de Economía Argentina, cuyo principal impulsor era el ingeniero Alejandro Bunge. Al igual que otros miembros de ese círculo, hacia 1943 Moyano Llerena asumió funciones gubernamentales, llegando a asesorar a Alfredo Gómez Morales, el conductor de la economía peronista entre 1949-1955. 
tos de Alejandro Bunge (uno de los maestros de Moyano Llerena), se consideraba menester aprovechar las ventajas comparativas de la industria argentina. Así, diversos trabajos publicados en Panorama de la Economía Argentina bregaban por la especialización en manufacturas intensivas en mano de obra calificada, barata en términos comparativos internacionales, y/o cuyas materias primas fueran abundantes en el país. Esta variante del CEI es denominada aquí «argumento de las ventajas comparativas». ${ }^{20}$

\section{Las instituciones promotoras del Programa}

No es posible analizar el Programa Conjunto sin considerar la emergencia de los «economistas profesionales», como parte del proceso de modernización de las ciencias económicas locales y del surgimiento de nuevas instituciones ligadas a ello. ${ }^{21}$ Algunas se vincularon al interés empresario al fundar sus posiciones corporativas sobre bases científicas. Es el caso del Instituto de Investigaciones Económicas y Financieras de la CGE (IIEF/CGE), creado a principios de 1962 para «consolidar el punto de vista de los empresarios», «estudiar los problemas del desarrollo económico nacional» y realizar una «contribución intelectual y empíricamente elaborada» a las discusiones sobre política económica. ${ }^{22} \mathrm{Su}$ «programa regular» de trabajos contaba con un «equipo estable de economistas y técnicos» enfocado en la investigación estadística, la preparación de informes de coyuntura, el asesoramiento a cámaras y federaciones empresarias, el intercambio de información con organismos públicos y privados nacionales e internacionales, el mantenimiento de un centro de documentación económico-financiera, la conducción de la revista CGE-200 millones y la organización de cursos y conferencias. ${ }^{23}$ Hasta 1968 , la dirección del instituto quedó a cargo del principal dirigente de la CGE, José Gelbard.

La creación de otras instituciones se vinculó con la ampliación de la intervención estatal, como es el caso de los organismos de planeamiento. Las demandas burocráticas que ella supuso hizo que estos reclutaran a los noveles expertos en economía, transformándose en plataformas institucionales para la puesta en debate de estrategias de desarrollo y de proyectos de reforma que los economistas profesionales estaban comenzando a entablar. Cabe

20. Contemporáneamente al despliegue del Programa Conjunto, Moyano Llerena presentaría sus planteamientos en el Informe sobre la industria argentina y los medios para su reactivación (1963), elaborado por la Comisión Honoraria de Reactivación Industrial, que aquel presidió.

21. Neiburg y Plotkin (2004).

22. Brennan y Rougier (2013, pp. 160-161).

23. CFI-IIEF/CGE (1963a, pp. 37-38). 
apuntar que la institucionalización del planeamiento fue impulsada por el gobierno de Frondizi mediante la creación de la Comisión Nacional de Administración del Fondo de Apoyo al Desarrollo Económico y del Consejo Nacional de Desarrollo (CONADE), e intensificada por sus sucesores: José Guido (1962-1963) y Arturo Illia (1963-1966). El CFI, un ente autárquico financiado por las provincias, fue otro de los organismos que protagonizaron el despliegue planificador. Su creación, concretada en 1959 durante la Tercera Reunión de Ministros de Hacienda, fue propuesta por Ferrer, entonces ministro de Economía y Hacienda bonaerense. En su Carta Constitutiva, este «organismo permanente de investigación, coordinación y asesoramiento», destinado a «promover el desarrollo armónico e integral del país», reconoce entre sus tareas el diagnóstico de situaciones económicas y la programación de actividades para atenderlas a medio y largo plazo.

\section{Los rasgos generales del Programa}

El Programa Conjunto se creó mediante un convenio firmado entre el CFI y la CGE, en abril de 1962, es decir, poco después del derrocamiento de Frondizi, cuando la crisis comenzaba a ser combatida con políticas cada vez más ortodoxas. Ya en los inicios de su gobierno, la CGE le había planteado que no podía «dilatarse la puesta en marcha del Plan de Desarrollo», ${ }^{24}$ cuya falta era criticada también desde Panorama de la Economía Argentina. Puede interpretarse que la creación del Programa pretendió saldar la deuda que había legado el frondicismo. Pero no fue este el primer esfuerzo de la CGE en esa dirección, pues, hacia 1960, buscando financiamiento y asistencia técnica para realizar un análisis exhaustivo de la actividad económica nacional y dar lugar a una efectiva programación, la entidad había presentado ante el Fondo Especial de Naciones Unidas un proyecto de programación decenal. Para abril de 1962, este se hallaba aún en consideración. En vistas de esa demora, se dio comienzo a una primera etapa mediante la acción mancomunada del CONADE y del CFI, que habían suscripto un convenio con la CGE para estudiar la capacidad industrial ociosa. Ese y el Programa Conjunto eran los dos «programas especiales» en los que se hallaba embarcado el IIEF/CGE a comienzos de los años sesenta. Para el funcionamiento del segundo se estipuló un plazo de dos años, dividido en cuatro etapas semestrales, que sería extendido hasta comienzos de 1965, cuando apareció el último informe del Programa. Se esperaba que los documentos producidos al finalizar cada etapa presentaran «una actualización y análisis de la situación existente en cada uno de los sectores considerados», estableciendo "progresivamente las bases de una progra-

24. Cottely (1959, p. 22). 
mación a corto plazo». ${ }^{25}$ La elaboración de esos informes aparecía, entonces, como lo que había podido hacerse en reemplazo del proyecto de Programación Decenal.

La conducción del proyecto recayó en la Comisión del Programa, conformada por el secretario general del CFI, Alfredo Calcagno; el presidente de la CGE, Idelfonso Recalde, ${ }^{26}$ y el director del Programa, Orlando d'Adamo, nombrado de común acuerdo para encargarse de los aspectos técnico-metodológicos. D'Adamo, un ingeniero agrónomo vinculado a Gelbard por haber dirigido la Federación de Productores de la Industria Forestal, había sido secretario técnico de la Presidencia al final del gobierno de Frondizi. ${ }^{27}$ En tanto, Calcagno había sido secretario ejecutivo de la Revista de Desarrollo Económico (1958-1959), una suerte de órgano de difusión de la Junta de Planificación Económica bonaerense, creada durante la gestión de Ferrer. ${ }^{28}$

Para sus tareas, la Dirección del Programa contrató a «distinguidas personalidades» de «medios profesionales y económicos» con acreditada «experiencia» y «capacidad» para "decir al país» qué correspondía hacer en cada sector. ${ }^{29}$ La mayoría eran ingenieros, contadores y economistas vinculados a la actividad académica, la función gubernamental y/o el mundo empresarial. Entre ellos había algunos ligados a los pioneros del CEI. De hecho, el estudio de Moyano Llerena brindó «asesoramiento estadístico» y aportó la colaboración de otro discípulo de Bunge, Horacio Mariscotti, quien entonces se desempeñaba como economista de la redacción de Panorama de la Economía Argentina $^{30}$ Por su parte, Ferrer, quien consideraba al CFI como «una poderosa herramienta para la programación del desarrollo», ${ }^{31}$ colaboró en el tercer informe. Junto a este, participaron del Programa otros expertos ligados a la red cepalina. Debe mencionarse el rol institucional de Calcagno y la cola-

\section{CFI-IIEF/CGE (1963a, p. 39).}

26. Este empresario textil fue un activo promotor de la exportación de esos productos, llegando a presidir la Cámara de Exportadores de la Argentina. De juventud socialista, había compartido con Rogelio Frigerio, principal ladero de Frondizi, su pertenencia al grupo de izquierda Insurrexit. En la segunda mitad de los años sesenta, presidió el IIEF/CGE, convirtiéndolo en un foro para economistas e intelectuales nacionalistas (Brennan y Rougier, 2013; Seoane 1998).

27. Además, desde 1949, ocupó diversos cargos públicos y ofició como docente en la Universidad Nacional de La Plata y como economista de la Organización de las Naciones Unidas para la Alimentación y la Agricultura (Seoane, 1998).

28. Tras la renuncia de Ferrer, este abogado platense hizo un posgrado en la Fondation Nationale de Sciences Politiques (París), graduándose con el trabajo Les organismes de développement économique régional en France. El CFI, al frente del cual fue nombrado a su regreso, publicó en 1963 una traducción de aquel.

29. CFI-IIEF/CGE (1962, p. 5).

30. Este ingeniero agrónomo había oficiado como secretario de redacción de la Revista de Economía Argentina (1945-1951) y había sido de jefe de asesores económicos de la Asociación de Industriales Metalúrgicos de la Unión Industrial Argentina (1958-1961) y asesor de la Secretaría Técnica de la Presidencia de la Nación (1961-1962), a cargo de D’Adamo.

31. Ferrer (1963, p. 242). 
boración de Ovidio Ventura, quien había sido miembro de la Comisión Interministerial de Comercio Exterior y asesor consultor argentino designado por la CEPAL (1958-1959), participando de las reuniones de expertos que habían coadyuvado al establecimiento de la ALALC. ${ }^{32}$

En el último informe, D'Adamo anunció el cierre de «una etapa de fructífera colaboración», iniciada «en un momento de gran incertidumbre para el país». Según apuntaba, la creación del IIEF/CGE había dado cuenta de la «serenidad» de los empresarios «frente a los problemas de la hora», contando «desde su inicio con la colaboración decidida e incondicionada» del CFI, bajo las administraciones de Calcagno y de su sucesor, Luis Rotundo. Estos habían comprendido «la importancia de la participación activa de organismos empresarios en la elaboración de estudios económicos sobre la realidad nacional». Agradecía también a los presidentes de la CGE y del IIEF/CGE «el intenso esfuerzo» puesto en financiar el Programa, destacándolo como «un caso único en la historia del empresariado argentino». ${ }^{33}$

Según el director del Programa, los documentos producidos pretendían brindar «un diagnóstico y una terapéutica de los problemas» que afrontaban «los principales sectores productivos», dando por descontado que, dada la experiencia «a la vez teórica y práctica» del «equipo de profesionales» que había realizado «una crítica positiva de los problemas inmediatos y mediatos» de la economía, tales reflexiones serían asidas por sus principales destinatarios: las autoridades económicas y las organizaciones políticas, laborales y empresariales. ${ }^{34}$ Sobre ello, debe mencionarse que el primer informe alcanzó amplia difusión, recibiendo numerosos comentarios en medios gráficos de todo el país, que fueron reproducidos celebratoriamente en el segundo. Respecto de ello, se explicitaba la voluntad de discutir los aportes del Programa ante un público amplio. En efecto, la Dirección se mostraba satisfecha con las «controversias» desatadas en «sucesivas reuniones», aclarando: «Estamos dispuestos (...) a aceptar las verdades de los demás». ${ }^{35}$

A esta caracterización hay que sumar señalamientos sobre la estructura editorial de los cuatro informes, cada uno compuesto de varios tomos subdi-

32. El resto de los participantes del Programa fueron: Francisco Aguilar, Hugo Barber, Pedro Barrios, Guido Belzoni, Juan Boggiano, Jorge Bolo, Juan Bonta, Arístides Brunelli, Gustavo Caraballo, Rodolfo Carrera, Zacarías Dawidowski, Jaime Delacre, Raúl Fernández, Martín Fuchs, Jorge Gardella, Horacio Giberti, Luis Henin, Israel Icikson, Santiago Isern, Leonardo Iurcovich, José Kestelman, Moisés Kostzer, César Lanfranchi, Alberto Lanusse, Simón Makler, José Marinelli, Orlando Martínez, Alejandro Menéndez, Bernabé Mindlin, Raúl Ondarts, Aldo Pecchini, Andrés Ringuelet, Mario Rossini, Julio Savon, Mario Seghezzo, Ideler Tonelli y Saúl Wittis.

33. CFI-IIEF/CGE (1965a, pp. 5-6).

34. Ídem.

35. CFI-IIEF/CGE (1963a, p. 56). 
vididos en «partes» temáticas. ${ }^{36}$ Los trabajos incluidos en ellas presentan una primera página donde se informa siempre de su carácter "preliminar» — sujeto a «cambios de fondo y de forma»- y, en algunos, los nombres de sus «responsables». Aunque no se considera adecuado leer los trabajos como la posición de las instituciones promotoras, tampoco se pretende analizar cada uno como la visión de su «responsable», pues el armado de los informes tuvo una Dirección a cargo y, en muchos casos, se evaden las marcas de autoría. ${ }^{37}$ En consecuencia, para enfatizar la existencia de un Programa coordinado, cuya conducción solicitó e hilvanó los trabajos, y teniendo presente la advertencia anterior, aquí son citados bajo las siglas de las instituciones promotoras. Como se verá, esta decisión no opaca las heterogeneidades presentes en el Programa.

\section{Integración y exportación}

Para comenzar, cabe apuntar que el trabajo inaugural del Programa Conjunto, probablemente a cargo de la Dirección, rescataba tanto los datos como el diagnóstico del mencionado informe CEPAL/Grupo Conjunto. ${ }^{38}$ Ese documento de 1958 no solo había aportado material estadístico inédito a escala latinoamericana, sino que también había introducido novedades en el plano del debate sobre estrategias de desarrollo. Aunque apelaba, en línea con el «cepalismo clásico», a profundizar la industrialización sustitutiva, apuntaba también distintos problemas acarreados por ese sendero: estructura de costos elevados (explicada por los excesos del proteccionismo) y mutación de la vulnerabilidad externa. Sostenía que una solución de fondo para el estrangulamiento de divisas exigía un mayor intercambio comercial con el resto del mundo, especialmente con Latinoamérica, y una diversificación de la canasta exportadora. ${ }^{39}$

Ahora bien, en lo que respecta al trabajo que abrió la iniciativa común entre el CFI y el IIEF/CGE, debe decirse que ligaba el «debilitamiento del co-

36. El primero, publicado en noviembre de 1962, corresponde al semestre 15 de junio 15 de noviembre de 1962. El segundo, de mayo de 1963, abarca el período 15 de noviembre de 1962-15 de mayo de 1963. El siguiente se publicó en enero de 1964, comprendiendo el semestre 15 de mayo-15 de noviembre de 1963. El último, publicado en enero de 1965, no indica fechas de referencia. Todos se presentaron en cuatro tomos, a excepción del cuarto, organizado en dos.

37. Los nombres de los «responsables» nunca son consignados en los índices analíticos. Asimismo, muchos trabajos carecen de título, adoptando la etiqueta genérica de la parte que los contiene, como ser «Industria textil».

38. «Evolución histórica de la economía argentina» (primer informe, tomo I, parte I). Aunque no se informa el responsable, dado que los siguientes informes comienzan con trabajos de la Dirección, este no debe haber sido la excepción.

39. CEPAL (1959). 
mercio exterior», explicado por la tesis prebischiana del deterioro de los términos de intercambio, al prolongado «estancamiento de la economía», cuyo comienzo databa en la crisis de 1949-1952. Ese debilitamiento había sido el «factor desencadenante» del verdadero «nudo de la crisis»: la larga «descapitalización de la economía». Esta era explicada por una expansión concentrada en los bienes de consumo, por la «falta» de «desarrollo paralelo» de los bienes intermedios y por la «insuficiencia» en la provisión bienes de capital, todo lo cual había creado la «vulnerabilidad» que se extendía a «toda la economía». Es decir, que la «debilidad» de esta era situada en la estructura industrial, a la que se sumaban deficiencias infraestructurales. En consecuencia, al igual que en el informe CEPAL/Grupo Conjunto, este trabajo promovía una política de «capitalización sujeta a un orden de prioridades», que respondiera a las «insuficiencias» estructurales, aunque advertía el «elevado contenido de divisas» de ese sendero, dada la importación de maquinaria y equipos complejos que requería. Así, apelaba a corregir ciertos problemas del sendero sustitutivo, sin correr a esa estrategia del centro de la escena. ${ }^{40}$

No obstante, ese trabajo también contemplaba otros señalamientos del informe cepalino, más próximos al emergente CEI. Por ejemplo, apuntaba que las dificultades de capitalización habían configurado en la industria «costos comparativamente elevados», gravando el «consumo interno» y limitando las «posibilidades de proyección al exterior». ${ }^{41}$ Esto fue retomado en el segundo informe, donde la Dirección puso mayor atención en los problemas del comercio exterior ${ }^{42}$ Allí, sostuvo que era preciso romper la política comercial exterior «liberal» e imponer un «cambio radical» en su orientación:

(...) la superación de la crisis del comercio exterior argentino puede ser lograda mediante un aumento de las exportaciones y ello a su vez debe estar coordinado hacia la diversificación de nuestra producción exportable, especialmente a través de un creciente incremento de las ventas al exterior de productos industriales, los cuales sin afectar las corrientes del intercambio tradicional, faciliten a la Argentina salir de su vieja estructura ajustada al principio clásico de la división internacional del trabajo (...). ${ }^{43}$

Tal diversificación debía «complementarse con una política comercial agresiva», orientada a la «defensa» de los precios y a «la conquista de nuevos mercados», enfrentando las «tendencias proteccionistas y discriminatorias de los países altamente desarrollados». En ese sentido, aunque advertía que la

40. CFI-IIEF/CGE (1962, pp. 35, 86, 103, 135-136).

41. Ibid. (p. 89).

42. «Situación actual de la economía argentina» (segundo informe, tomo I, parte I).

43. CFI-IIEF/CGE (1963a), pp. 129-130. 
ALALC estaba en un «punto crítico», por ciertas complicaciones del mecanismo negociador, la Dirección la veía como «tal vez uno de los pocos caminos» que tenía la región para «alcanzar las metas de los verdaderos desarrollos nacionales», sorteando la «limitación» que la «estrechez» del mercado interno imponía al desenvolvimiento industrial por las «dificultades crecientes» que debía enfrentar cada país para expandir sus ingresos por exportación. Cabe señalar que, para mayo de 1963, cuando se publicó el segundo informe del Programa, el documento que Prebisch presentaría en Mar del Plata había sido enviado ya a los gobiernos latinoamericanos. De hecho, era citado en este trabajo de la Dirección, aunque respecto de la correlación desarrollo económico-desarrollo social. Ahora bien, pese a lo dicho sobre la diversificación exportadora, al referirse al «plan inmediato» que debía reemplazar al de «desarticulación de la industria nacional», no se contemplaba la promoción de las exportaciones manufactureras. ${ }^{44}$

En el tercer informe, la Dirección retomó la cuestión de la integración latinoamericana ${ }^{45}$ Según señalaba, el mercado interno de los países latinoamericanos, «principal consumidor» de manufacturas argentinas, «única área» en la que podían imponerse ciertas «leyes de juego» y base exclusiva para la expansión hacia los mercados externos, no había recibido la «atención debida», pues primaba una «mentalidad» que debía ser «urgentemente modificada». Esta afirmación, en línea con el avance de la integración regional y con la autorrevisión cepalina, sintonizaba con un fuerte cuestionamiento al proteccionismo de los «países industrializados», enmarcado en la convocatoria a la primera reunión de la UNCTAD. También aquí eran retomados los argumentos expuestos por Prebisch en 1963, destacándose a la ALALC como «instrumento esencial para el desarrollo» de los países latinoamericanos. ${ }^{46}$ Tal énfasis se derivaba del siguiente diagnóstico:

[...] cuando el país avanza y elimina todo aquello que era posible eliminar, se llega a la etapa difícil, al verdadero estrangulamiento del comercio exterior, porque [...] las industrias pesadas en general, representan un obstáculo insalvable en cuanto al monto de inversiones, como para hacer posible soluciones fáciles. ${ }^{47}$

Alcanzada esa «nueva congestión en la demanda de divisas», que no podía ser «compensada» sustitutivamente, la Dirección afirmaba:

44. CFI-IIEF/CGE (1963a, pp. 129-130, 134, 156).

45. «Consideraciones sobre la situación actual de la economía argentina» (tercer informe, tomo I, sección A, parte I).

46. CFI-IIEF/CGE (1964a, pp. 21, 23).

47. Ibid. (p. 28). 
[...] es indispensable llegar incluso al subsidio de las exportaciones industriales para que el crecimiento de la industria liviana siga teniendo algún efecto beneficioso en el balance comercial del país. Es decir, superada la etapa de la fácil sustitución de importaciones, el crecimiento del sector industrial de consumo interno debe tener por lo menos, la consecuencia de originar un ingreso de divisas como resultado de las exportaciones del mismo sector. ${ }^{48}$

Y agregaba que, de subsidiarse las exportaciones industriales, como Estados Unidos hacía con las agropecuarias, Argentina podría alcanzar un mayor equilibrio comercial, generando las divisas requeridas por el avance de la integración manufacturera.

En el último informe, que pretendía condensar las reflexiones de sus predecesores, la Dirección coordinó la parte inicial, presentada en nueve capítulos a cargo de distintos colaboradores del Programa. ${ }^{49}$ En los dos primeros, firmados por D'Adamo, se postulaba a la integración regional como la «única respuesta», considerando que aun cuando en 1964 las exportaciones industriales argentinas habían caído, la ALALC había permanecido como su «mejor mercado». ${ }^{50}$ En ese sentido, se mencionaba la «imperiosa necesidad» de reactivar el régimen de draw-back y de activar la desgravación impositiva y la prefinanciación y financiación de exportaciones industriales. También se seguía aquí a Prebisch, aunque citando un artículo de 1961, donde aquel aclaraba que, dado que la vulnerabilidad externa era estructural, exigía soluciones de esa naturaleza. ${ }^{51}$

En suma, los trabajos de la Dirección del Programa presentan un claro eco de la autorrevisión cepalina, en línea con el emergente CEI. Ahora bien, respecto de los debates sobre estrategias de desarrollo contemporáneos al despliegue de esa iniciativa, más relevantes que aquellos resultan los trabajos dedicados específicamente al tema del comercio exterior, a cargo de Jorge Gardella, José Kestelman y del mencionado Ovidio Ventura. ${ }^{52}$ Ya en el primer informe, estos sostuvieron que aunque el «factor esencial» de la «desfavorable» evolución del balance de pagos había residido desde 1951 «fundamentalmente» en la «insuficiencia» exportadora, la política sustitutiva no había mantenido un

48. Ibid. (pp. 28-29).

49. «Análisis de la política económica» (cuarto informe, tomo I, parte I).

50. CFI-IIEF/CGE (1965a, pp. 8-9, 19).

51. Se trata de «El falso dilema entre desarrollo económico y estabilidad monetaria», publicado en el Boletín Económico de América Latina de marzo de 1961.

52. Miembro del Instituto de Estudios Económicos de Buenos Aires desde 1951, Gardella fue asesor del Ministerio de Relaciones Exteriores del gobierno de Frondizi, participando de la Conferencia de la ALALC de 1961. Por su parte, Kestelman era un doctor en Ciencias Económicas vinculado profesionalmente a distintas empresas y asesoraba a la CGE desde 1955. 
«ritmo adecuado a las nuevas necesidades del desarrollo». ${ }^{53}$ En virtud de ello, apelaban a promover «notables incrementos» en la producción agropecuaria y un proceso sustitutivo "efectivo», «respetando las prioridades correspondientes»: siderurgia, química pesada, petroquímica, celulosa y papel. Empero, aclaraban que el fin de tales sustituciones no era reducir importaciones, sino permitir que se efectuaran otras «insustituibles», que eran «necesarias para continuar con los planes de crecimiento económico», señalamiento presente ya en el informe CEPAL/Grupo Conjunto. ${ }^{54}$

Ahora bien, según Gardella, Kestelman y Ventura, esas directrices no eran suficientes, pues el «enorme» déficit de 1961 había colocado al país ante «la trágica alternativa de incrementar radicalmente sus exportaciones o paralizar indefinidamente el crecimiento $» .{ }^{55}$ Especialmente, en una coyuntura signada por el «problema» que suponía la política del Mercado Común Europeo (MCE) para las exportaciones argentinas. ${ }^{56}$ Desde su perspectiva, la insuficiencia del comercio exterior se vinculaba con el criterio «excesivamente proteccionista» que había primado en la política comercial durante la aplicación del control de cambios y aún luego de su abandono, permitiendo «el desarrollo de industrias sobre bases poco económicas y desvinculadas de toda preocupación por desenvolverse sobre la base de costos competitivos». Además, apuntaban que la «liberalización de los cambios» no había introducido modificaciones sustanciales, exhibiendo "poca eficacia» para estimular exportaciones. En cambio, destacaban la «gran efectividad» de las medidas adoptadas durante 1962, centralmente el régimen de draw-back y la financiación de exportaciones, pues promovían la exportación de "productos no tradicionales», cuya repercusión en el intercambio comercial esperaban se hiciera sentir pronto, sobre todo si se aprovechaban los «beneficios» de la ALALC. Esas herramientas debían «complementarse» con «medidas administrativas, fiscales y financieras» y con un sistema de cambios orientado a «estimular las exportaciones de productos manufacturados y "no regulares"»..$^{57}$

En síntesis, como en los trabajos de la Dirección, el planteamiento de estos expertos resultaba muy similar al del informe CEPAL/Grupo Conjunto, pues aunque las críticas al proteccionismo se maridaban con la expansión de

53. «El papel del comercio exterior en el desarrollo económico» (primer informe, tomo I, parte II). CFI-IIEF/CGE (1962, pp. 186-187).

54. Ibid. (p. 193).

55. Ibid. (p. 191).

56. El proteccionismo del MCE, creado por el Tratado de Roma (1957), fue rápidamente identificado como una amenaza para las exportaciones agropecuarias argentinas, pero también como ejemplo de integración económica regional a seguir. Así lo señaló Ventura en una mesa redonda organizada por Panorama de la Economía Argentina, cuya relatoría, titulada «La Zona de Libre Comercio», fue reproducida en el n. ${ }^{\circ} 13$ (1960) de esa revista.

57. CFI-IIEF/CGE (1962, pp. 191, 211, 213-215, 220-221). 
las exportaciones manufactureras, esto estaba subordinado a atenuar el nuevo tipo de vulnerabilidad, sin articularse con la estrategia industrial, que seguía dominada por la corrección del proceso sustitutivo. Sin embargo, en estos casos, el fomento de las exportaciones industriales presentaba mayor énfasis y posibilidades temporalmente más próximas que en aquel documento de 1958. Esto resulta comprensible a la luz de la coyuntura que, signada por la crisis de 1962-1963 y por la activación de la ALALC, convirtió a la exportación manufacturera en algo más que una posibilidad futura.

Ya en el trabajo que Gardella, Kestelman y Ventura aportaron al segundo informe, las condiciones para una salida industrial-exportadora aparecían claramente indicadas. ${ }^{58}$ Según apuntaban, la crisis había «movido» a muchos industriales a pensar en la exportación «como una manera de eliminar o disminuir sus stocks de mercaderías». A ello añadían consideraciones menos coyunturales, como la «imperiosa necesidad de modificar» la estructura «vulnerable» de la distribución de las exportaciones por productos y por áreas, para adecuarla a las «actuales tendencias del comercio internacional». ${ }^{59} \mathrm{La}$ dirección que debía tomar esa modificación sintonizaba tanto con la reseña que presentaban esos expertos de la estrategia francesa, como con lo propuesto por la Dirección del Programa: la diversificación de las exportaciones debía producirse por el incremento de las ventas de bienes manufacturados. Respecto a los destinos de exportación, señalaban que, aunque la ALALC no tenía aun la incidencia de otras áreas, constituía una «posible solución», pues podía transformarse en «importante receptora» de productos argentinos. En esa línea, apuntaban que «estimular» la producción «en más vasta escala y sobre bases más competitivas» era uno de sus fines. Esto suponía un funcionamiento basado en consideraciones de especialización, a lo cual apuntaban los acuerdos de reciprocidad de la ALALC, destinados a favorecer la complementación de etapas de fabricación entre el mismo sector de distintos países y a «armonizar» modelos de un mismo producto, para «alcanzar la mayor eficiencia, abaratar los costos, obtener el mejor aprovechamiento de los recursos productivos y expandir su actividad productora». Asimismo, sostenían que la «multiplicación» de esos convenios contribuiría a resolver deficiencias estructurales, provenientes «de políticas de substitución de importaciones a cualquier costo» y mantenidas durante plazos que excedían «lo razonable y conveniente». ${ }^{60}$

Ahora bien, para Gardella, Kestelman y Ventura, la diversificación exportadora dentro de la ALALC era especialmente significativa para la producción de insumos básicos, bienes intermedios y de capital, pues exigía

58. «Comercio exterior» (segundo informe, tomo I, parte III).

59. CFI-IIEF/CGE (1963a, pp. 222, 312).

60. Ibid. (pp. 236, 250, 263, 301-302). 
«grandes inversiones y una alta tecnología», solo alcanzables «dentro de ciertas seguridades» y en mercados de «dimensión adecuada». Particularmente, señalaban que esa posibilidad era relevante para Argentina, que había «alcanzado la casi total substitución» en las industrias livianas y necesitaba, para «pasar a la etapa de producción de bienes intermedios primero y de bienes de capital o de la industria pesada después», «escalas de producción más amplias», tal como ofrecía la integración de «los mercados nacionales en un solo mercado común». ${ }^{61}$ Este énfasis en las «industrias básicas» se vinculaba con la secuencia de desarrollo de Francia, donde, antes de la liberalización cambiaria, se había privilegiado el avance de esas ramas, permitiéndole al país «enfrentar» la competencia internacional «en condiciones de costos, productividad e innovación eficientes». ${ }^{62}$ Así, mientras que la especialización productiva quedaba relegada a un plano general, las consideraciones de eficiencia eran rápidamente hilvanadas con la secuencia de desarrollo y asociadas al despliegue de las «industrias básicas», de manera afín al argumento de la complementariedad. En ese sentido, se avanzaba más que la Dirección, pues el aliento a las exportaciones manufactureras aparecía articulado con la estrategia de industrialización, por la misma vía que desde 1958 venía impulsando la red cepalina y que, contemporáneamente, alcanzaría una forma más acabada con la publicación del libro de Ferrer.

No sorprende que el tercer informe del Programa incluyera un aporte del exministro bonaerense. ${ }^{63}$ Retomando los argumentos presentados en La economía argentina, Ferrer señalaba que la «insuficiente» integración manufacturera del país, junto al «estancamiento prolongado de una capacidad de importar exclusivamente apoyada en (...) las exportaciones agropecuarias tradicionales», eran «condicionantes fundamentales» del estancamiento de los quince años previos. Empero, ese diagnóstico no conducía hacia un planteo autarquista, pues Ferrer advertía que «no podría concebirse una sustitución total de importaciones» en maquinarias y equipos. En vistas de ello, apuntaba los problemas que suponía transformar el ahorro interno en divisas, para efectuar esas «indispensables importaciones». Contemplando esos puntos, concluía:

El prolongado estancamiento de la capacidad de importar [...] revela la pérdida de la capacidad dinámica del sector externo y es obvio que el nivel de eficiencia de la economía argentina y sus posibilidades de crecimiento se verían reforzadas con una más activa participación en el comercio internacional y, particularmente, dentro del comercio interlatinoamericano. Por el otro, ha creado dificultades en

61. Ibid. (pp. 249, 302).

62. Ibid. (p. 216).

63. «El financiamiento externo en la formación de capital de la Argentina. Sus proyecciones» (tercer informe, tomo I, sección A, parte III). 
el abastecimiento de maquinarias y equipos importados, aparte de obligar a una compresión excesiva de las importaciones corrientes determinando, en muchos casos, el establecimiento de líneas de producción que sustituyen importaciones a un bajo nivel de eficiencia. El proceso de industrialización y de integración de la estructura económica del país ha sido fuertemente dificultado por la rigidez del sector externo y es obvio que la transformación necesaria podría facilitarse en condiciones más dinámicas de ese sector. De esto surge la importancia de expandir las exportaciones y consecuentemente la capacidad de importar. Esto implica, al mismo tiempo, una transformación profunda de la composición de las exportaciones. $^{64}$

Así, Ferrer desplegaba el argumento de la complementariedad en el seno del Programa.

En ese mismo informe y en el siguiente, Gardella, Kestelman y Ventura presentaron trabajos individuales. En el de 1964, tras mencionar las consecuencias del MCE sobre las ventas externas argentinas, Kestelman afirmaba que «el proceso iniciado de exportación de productos industriales» era «un proceso a mediano y largo plazo», que había que «acelerar» mediante las posibilidades brindadas por la ALALC y la UNCTAD. Asimismo, consideraba «indudable» que la «estrategia exportadora» exigía no solo «aumentar el campo de los productos de exportación», sino también «la rápida utilización de las ocasiones [...] para abrir nuevos mercados». ${ }^{65}$ Siguiendo las recomendaciones marplatenses de Prebisch, destacaba a Europa Oriental, región con la que el intercambio comercial argentino registraba antecedentes positivos.

Ya en el informe de 1965, Kestelman señaló que Argentina había sido el país que más había aprovechado la «reactivación del intercambio comercial» latinoamericano, aunque advertía que la ALALC estaba ingresando en «uno de sus períodos más críticos». ${ }^{66}$ Con todo, reafirmaba que el comercio intrazonal era «el camino más indicado para superar los problemas de estrangulamiento externo [...], intensificando el intercambio de productos manufacturados» ${ }^{67}$

Por su parte, en el tercer informe, y retomando la tesis marplatense de Prebisch, Gardella advertía que las desfavorables perspectivas del comercio internacional presentaban un grave riesgo para el crecimiento de las regiones «poco desarrolladas», especialmente Latinoamérica. ${ }^{68}$ Sobre ese diagnóstico sombrío, apuntaba dos consideraciones: la primera, «la necesidad de promover medidas concretas tendientes a corregir la insuficiencia dinámica» del sector externo; la segunda, que el «problema» del deterioro de los términos del

64. CFI-IIEF/CGE (1964a, pp. 288, 307, 309).

65. CFI-IIEF/CGE (1964b, pp. 152, 167).

66. Afirmaba que su desarrollo no estaba alcanzando el ritmo requerido por sus miembros, siendo «poco» lo logrado en cuanto a complementación industrial.

67. CFI-IIEF/CGE (1965a, pp. 113, 117, 132).

68. «Comercio exterior» (tercer informe, tomo I, sección B, parte VI). 
intercambio no podría resolverse «espontáneamente ni circunscribirse su solución a políticas nacionales aisladas». Respecto al caso argentino, sostenía que integraba el grupo que había presentado «una disminución más acentuada del volumen de exportaciones y una baja mayor aún en el poder de compra externo». En esa línea, afirmaba que la «clave» residiría en la «débil exportabilidad» de actividades con «alto» coeficiente de insumos importados. Gardella vinculaba ese problema al grado de interdependencia sectorial, pues el desarrollo industrial había comenzado en sectores con alto grado de eslabonamiento anterior y, por ende, con «alto coeficiente de dependencia de la importación». ${ }^{69} \mathrm{Al}$ respecto, sostenía:

Esta situación plantea la necesidad de concebir respuestas que puedan sistemáticamente eludir o superar este problema de la dependencia de los sectores industriales, de la manufactura final e intermedia, del abastecimiento de divisas. [...] la única forma de contrarrestar sistemáticamente los aumentos de importaciones provocados por el crecimiento de las actividades de las industrias de manufacturas final e intermedia, parece ser la de explotar en profundidad el rápido crecimiento de una serie de industrias con alto grado de eslabonamiento anterior, es decir con elevada proporción de insumos de importación bajo la condición de que parte de su producción pueda ser exportada. Es decir, establecer en términos de divisas un crecimiento autoliquidable que fue precisamente el que sirvió a los primeros países industriales para sustentar su rápida industrialización. ${ }^{70}$

Así, partiendo de un diagnóstico que identificaba problemas en la secuencia de desarrollo seguida, Gardella enriquecía los argumentos favorables a una salida que complementara la integración manufacturera con la exportación de productos industriales, especialmente, dado el «considerable» interés que le asignaba a la ALALC. Para «mejorar el intercambio intrazonal de manufacturas», apuntaba medidas como el «trato preferencial», la reestructuración arancelaria y, «en la medida de lo posible», la adopción de un «tipo de especialización aconsejable por un estudio global de sus economías conjuntas». ${ }^{71}$ Estas consideraciones se inscribían en otras más generales acerca del comercio internacional, que seguían lo planteado por Prebisch en 1963 y cobraban especial sentido al calor de la UNCTAD. A escala nacional, Gardella recomendaba: promoción sostenida mediante medidas tendientes a diversificar tanto los productos como el número de empresas exportadoras y su radio de

69. Arribaba a esta conclusión, destacando el «considerable interés» de la tabla sobre grado de interdependencia promedio por sectores, confeccionada en 1958 por Hollis Chenery y Tsunehiko Watanabe para Italia, Japón y Estados Unidos y transcripta por Albert Hirschman en La estrategia del desarrollo económico. Este había destacado su utilidad para identificar «industrias clave». Otro experto del Programa, cuyos aportes se analizarán pronto, había apelado a estas referencias en el informe previo.

70. CFI-IIEF/CGE (1964b, pp. 47, 56, 71, 73).

71. Ibid. (p. 75). 
acción en el exterior; perfeccionar y acelerar los estímulos vigentes, y apoyar selectivamente a empresas que realizasen un mínimo de ventas sobre los mercados extranjeros.

En tanto, Ventura abordó en el tercer informe el comercio de los «productos básicos de exportación tradicional», cuyo análisis consideraba necesario, pues la «deseable» exportación de manufacturas no había logrado «aún la importancia que le permitiría el nivel de desenvolvimiento industrial alcanzado». ${ }^{72}$ Allende ese reparo, afirmaba:

Es principalmente por la mejoría de nuestros términos del intercambio y mediante el aumento de nuestros saldos exportables y del grado de diversificación e industrialización de nuestras exportaciones, que conseguiremos mejorar la suerte de nuestro país, [...] sin descartar la necesidad de lograr un aumento de la eficiencia productiva en todos los sectores [...], sin cuya contribución sería difícil alcanzar los objetivos señalados. ${ }^{73}$

Es decir que en aquel «aún» residía una de las llaves para mejorar la «suerte» nacional, tratándose, luego, de acortar su duración. De hecho, Ventura señalaba que el desarrollo de industrias de exportación era, junto a la diversificación de la producción agrícola exportable, «el remedio más eficaz» para evitar el «serio inconveniente» de la «inestabilidad» de ingresos por exportación. ${ }^{74}$

Ya en el último informe, Ventura afirmaba que, según había estimado Prebisch, la continuación de las tendencias vigentes del comercio internacional generaría una «brecha» que no podría colmarse siquiera vía cooperación financiera internacional, debiendo «cubrirse principalmente con el aumento de las exportaciones industriales». Incluso, aunque reconocía la formación de una «nueva conciencia» relativa al comercio internacional, aclaraba que en instancias internacionales, como el Acuerdo General sobre Aranceles Aduaneros y Comercio (GATT, por sus siglas en inglés) y la UNCTAD, persistían «inconvenientes» para avanzar en ese sentido, relativos a la posición de los «países industrializados» frente al «problema de las preferencias»». ${ }^{75}$

En base a los trabajos analizados, puede afirmarse que con el correr de los informes comenzaron a resonar en el Programa Conjunto los interrogantes, diagnósticos y prescripciones que estaban configurando el CEI. En principio, el fomento de las exportaciones manufactureras apareció ligado casi exclusivamente al estrangulamiento externo. Cuando era vinculado a la reso-

72. «El comercio internacional de nuestros productos básicos. Tendencias y perspectivas» (tercer informe, tomo I, sección B, parte VI).

73. CFI-IIEF/CGE (1964b, pp. 79, 90).

74. Ibid. (p. 94).

75. CFI-IIEF/CGE (1965a, pp. 81, 94). 
lución de problemas del sector industrial, el carácter de estos era coyuntural, como la retracción del consumo doméstico de 1962-1963. No obstante, el aliento de esas exportaciones pronto comenzó a articularse con deficiencias estructurales del sendero industrializador. En esa línea, la activación de la ALALC, en una coyuntura de replanteo del comercio internacional, empezó a aparecer como alternativa ante la estrechez del mercado interno, que obstaculizaba el avance de la integración manufacturera. Por esa vía, la salida fabril al exterior se anudó con consideraciones de eficiencia y de costos, nodales para la emergencia del CEI. Ahora bien, debe advertirse que estas eran vinculadas a la integración sectorial, vía desarrollo de las industrias «básicas», es decir, de manera similar a la articulación propuesta por Ferrer, quien además colaboró con el Programa. Empero, el argumento de la complementariedad no fue la única variante del CEI que halló cabida en el seno de esta iniciativa.

\section{La granja del continente}

Otro colaborador del Programa Conjunto fue Simón Makler, un doctor en Ciencias Económicas que había conducido el Departamento de Asesoría Económica durante el gobierno de Frondizi. ${ }^{76}$ A diferencia de Gardella, Kestelman y Ventura, Makler no abordó un tema específico, sino que aportó dos amplios trabajos a los informes de 1963 y 1964: el primero centrado en el sector industrial; el segundo, en la estrategia de desarrollo en general. Puesto que se solapan bastante, aquí serán analizados en conjunto. A ellos se suma otro de carácter sectorial, incluido en el quinto informe. ${ }^{77}$

Proponiéndose revisar los aspectos cualitativos de la estrategia de desarrollo, Makler partía de las «modernas» teorías sobre crecimiento desequilibrado y eslabonamientos productivos, retomando el concepto de «industrias principales o líderes» (caracterizadas por su «demanda 'explosiva») de Walt Rostow y la tabla de interdependencia sectorial construida por Hollis Chenery y Tsunehiko Watanabe y reproducida por Albert Hirschman en su famoso libro de $1958 .^{78}$ Según apuntaba, la falta de una clara noción de las «dependencias» entre sectores económicos y de la «vulnerabilidad creada» en ellos por los «desequilibrios no deliberados y mantenidos por períodos lar-

76. Además, fue investigador en distintos institutos de la Universidad de Buenos Aires y elaboró las tesis presentadas por la Universidad Nacional de Rosario ante el Segundo Congreso Latinoamericano de Facultades de Ciencias Económicas sobre Mercado Común (1960).

77. «Consideraciones sobre la evolución de la industria argentina y sus perspectivas» (segundo informe, tomo III, parte I); «Notas para una estrategia del desarrollo económico argentino» (tercer informe, tomo I, sección A, parte II); «Actividades industriales» (cuarto informe, tomo II, parte II).

78. CFI-IIEF/CGE (1963b, pp. CXLIV-CXLV). 
gos» representaba una de las «razones principales» del estancamiento argentino. ${ }^{79}$ Era preciso determinar qué relaciones de secuencia habilitaban la continuación del proceso de desarrollo, es decir, establecer un orden de prioridades. Para ello, tomaba como base estadística el informe CEPAL/Grupo Conjunto y comparaba sus proyecciones con los datos de 1962.

Sobre esas bases, Makler ensayaba una revisión histórica, según la cual, el hecho de que la expansión agropecuaria no hubiese acompañado a la industrial era «el gran factor de vulnerabilidad» económica, subyaciendo como «determinante» del estancamiento. En consecuencia, afirmaba que el primero de esos sectores era «esencial» para la estrategia de desarrollo, pues abrigaba «posibilidades explosivas de expansión con imprevisibles consecuencias de inducción sobre el resto de la economía». Según reconocía, tal afirmación enfrentaba «prejuicios»y «tabúes». Contra estos, apuntaba que la importancia del agro no significaba un «retroceso» en el desarrollo porque, dadas las crecientes necesidades técnicas e infraestructurales que requería, era compatible con la integración manufacturera. Asimismo, tras señalar que el aumento de las exportaciones repercutiría en el resto de la economía, advertía que el agro explicaba el $95 \%$ de aquellas, no siendo «previsible» que los productos no tradicionales pudieran «reemplazar su magnitud» a corto plazo ${ }^{80}$ Involucrándose en un amplio debate, Makler sostenía que el «derrotismo» de Prebisch respecto del incremento del conjunto de las exportaciones latinoamericanas, había sido «mecánicamente» trasladado a las posibilidades argentinas. ${ }^{81}$

Por su parte, la comparación con las proyecciones del informe CEPAL/ Grupo Conjunto arrojaba un crecimiento del PBI muy inferior al allí estimado. Esto era explicado, principalmente, por el mal desempeño industrial, asociado a una deficiente distribución sectorial del capital. Makler sostenía que, en el orden de prioridades, la promoción agropecuaria debía ser seguida por el equipamiento de los sectores de infraestructura y del propio sector manufacturero, donde visualizaba un «campo» para la sustitución, especialmente importante en siderurgia y otras ramas intermedias. Desde su óptica, esto se vinculaba con una serie de «fallas» de enfoque que habían inspirado las políticas de los distintos gobiernos. Por ejemplo, el «impulso indiscriminado a la actividad industrial sin establecer un orden de prioridades que promoviese especialmente los sectores necesarios para un crecimiento integrado» y la «aplicación de una política proteccionista simple a la industria sin tener en cuenta

79. CFI-IIEF/CGE (1964a, p. 218).

80. Estos postulados se fundaban en el informe «Aspectos del desarrollo industrial en la Argentina: Informe al Gobierno Argentino y a la ICA» (1961), realizado por la consultora estadounidense Arthur Little Inc.

81. Seguía a Charles Kindleberger, por haber «puesto en duda lo sentado por Prebisch», y a Hirschman, por el restablecimiento del efecto de la competencia, que consideraba omitido por el cepalino (CFI-IIEF/CGE, 1964a, pp. 223-224, 227, 256. 
la necesidad de propender simultáneamente al mejoramiento de costos y calidades», todo lo cual había desanimado a los sectores de productos intermedios. A ello sumaba la «falta de noción de la importancia de la expansión de sectores que inducen o propagan el desarrollo», el «abandono de la capitalización de los sectores de infraestructura» - convertidos en «factor de vulnerabilidad interna»- y la «falta de una política de promoción del comercio exterior», que había transformado a «la escasez de divisas en el factor de vulnerabilidad externa del desarrollo»..$^{82}$

Respecto de esas falencias, Makler afirmaba que «los esfuerzos más serios» habían sido realizados por el gobierno de Frondizi ${ }^{83}$ Según apuntaba, aunque la «crisis agrícola» de 1951 había expuesto la «difícil» situación del país, obligando ya a la adopción de una política dirigida a la capitalización de los sectores básicos y la producción de bienes durables, esta no había tenido demasiado éxito hasta 1958, cuando, con la liberación del «alterado» sistema de precios internos, había adquirido su expresión «más definida». ${ }^{84}$ De hecho, en línea con la política frondicista, fincaba esperanzas en que una «política de aceleración de la inversión reproductiva», basada en el «aporte» del capital extranjero y que priorizara los sectores con un «papel inductivo de importancia», condujera a la "superación de la "impasse" de la economía nacional». ${ }^{85}$

Ahora bien, dentro del sector industrial, Makler asignaba «primera prioridad» a los sectores productores de bienes de capital e intermedios, dados sus «crecimiento dinámico» $\mathrm{y}$ «alto grado de eslabonamiento posterior y anterior». Esto surgía de una interpretación, según la cual, el período cerrado con la asunción de Frondizi se había caracterizado por la formación de un «estrangulamiento exterior e interior» y por la «falta de un orden de prioridades» para el desarrollo, diagnóstico afín al del informe CEPAL/Grupo Conjunto. Asimismo, consideraba que el hecho de que se hubieran sustituido las «industrias livianas» antes que las «básicas» explicaba parcialmente la «extrema vulnerabilidad a las fluctuaciones en la provisión de materias primas y equipos de capital» a la que el país estaba expuesto, cuyo «otro extremo» era la «disminución excesiva en la capacidad de importar». Según sostenía, aunque la tendencia a disminuir la importancia del comercio exterior con relación al PBI era «normal» en los procesos de desarrollo, posición contrastante tanto con los planteos de Panorama de la Economía Argentina como con la autorrevisión cepalina, Argentina representaba un caso «excepcional», pues no solo exhibía una disminución relativa «notable», sino también una «baja importante» en términos absolutos. ${ }^{86}$

82. Ibid. (pp. 111-112, 182-184).

83. CFI-IIEF/CGE (1964a, p. 184).

84. CFI-IIEF/CGE (1963b, pp. XCVII, CX).

85. CFI-IIEF/CGE (1964a, p. 184).

86. CFI-IIEF/CGE (1963b, pp. CVI, CVIII, CXL, CXLIV-CXLIVI). 
Para Makler, lo anterior daba cuenta de que el «factor estímulo» de la economía se había desplazado del sector externo hacia el consumo interno. En relación con ello, afirmaba que el crecimiento manufacturero se había realizado al amparo de «un proteccionismo, de hecho y de derecho, absolutamente indiscriminado» y de un mercado en el que «el predominio de la demanda» había debilitado «el aguijón de la competencia como factor de mejoramiento de calidades y reducción de costos». Luego, criticaba el sistema arancelario vigente, pues en vez de fijar una «lógica protección decreciente en el tiempo, como para acelerar el proceso en que una industria se pone en condiciones competitivas», actuaba con un «simple espíritu promocional, sin una visión planeada del futuro» y dirigido a «proteger lo existente». A su vez, cuestionaba la «escasa preocupación» puesta en la «calidad» y en la «productividad general de la industria». ${ }^{87}$

Como se ve, aunque reivindicaba la política frondicista, Makler criticaba profundamente el esquema proteccionista sobre el cual se había desplegado la industrialización hasta el presente. Dentro de su planteamiento, eso no representaba ambigüedad alguna, pues adjudicaba a la «política de precios deformados» el haber impedido que la expansión a «etapas más complejas» —inducida por la ampliación de un sector que demandaba la «creación» de su proveedor - se hubiera producido «en la forma y con la intensidad necesaria». Por ello, la «estrategia de desarrollo industrial» que proponía para «la satisfacción de las necesidades nacionales» privilegiaba la integración manufacturera. Según entendía, esas necesidades ataban el futuro industrial a la demanda interna, enfrentándose así a quienes, motivados por las recientes «experiencias alentadoras», afirmaban que las exportaciones manufactureras representaban «una base futura de la expansión industrial». De hecho, advertía que los montos que tendrían que lograr las exportaciones manufactureras para conducir el «ritmo» de crecimiento del sector al nivel necesario para un mejoramiento económico sustancial no eran racionalmente esperables en un futuro inmediato. ${ }^{88}$ En esa línea, la comparación con las estimaciones cepalinas mostraba que las exportaciones del rubro «otros productos» habían quedado «muy atrás» de lo proyectado, especialmente por la «defección» de las manufacturas, subgrupo en el que la proyección concentraba casi todo el crecimiento ${ }^{89}$ Por ende, Makler apuntaba que, «sin perjuicio de los esfuerzos más decididos para fomentar el comercio exterior», la promoción industrial debía orientarse hacia rumbos inmediatamente más compatibles con las «necesidades nacionales»: la producción de bienes intermedios y de capital. ${ }^{90}$

87. Ibid. (pp. CIX, CXXXVI-CXXXVII).

88. Ibid. (pp. CXXIII, CXL-CXLI).

89. CFI-IIEF/CGE (1964a, p. 163).

90. CFI-IIEF/CGE (1963b, p. CXLI). En unas jornadas organizadas en 1963 por la Confederación General del Trabajo, Makler sostuvo que las exportaciones manufactureras eran un espejismo (Rougier y Odisio, 2017). 
Resumiendo, aunque este experto reconocía los avances de la exportación manufacturera, no consideraba que fuera ese el sentido que debía privilegiar la política industrial. El orden de prioridades exigía avanzar en la integración sectorial. Así, Makler guardaba esperanzas en que los males ocasionados por el proteccionismo fueran subsanados sin abandonar la estrategia sustitutiva. En esa dirección, destacaba los frutos positivos de las políticas frondicistas, argumentando que habían contribuido «con un criterio selectivo a subsanar las fallas estructurales» del sector. ${ }^{91}$ En su planteo, esa línea era peculiarmente combinada con la promoción de las exportaciones agropecuarias.

Empero, Makler ofrecía otros comentarios sobre las exportaciones manufactureras, cuya promoción debía ser planificada y centralizada, aunque no resultara prioritaria. En particular, apuntaba que «la perspectiva de exportar, especialmente a los mercados latinoamericanos, sin perjuicio de los europeos y estadounidense», se presentaba ante la industria nacional llena de posibilidades, en particular si se realizaban esfuerzos para elevar a niveles internacionales los costos y calidades, sobre todo en sectores que brindaban posibilidades competitivas mayores. ${ }^{92}$ Especificando, señalaba que el aumento de las exportaciones basadas en las ventajas competitivas de la industria argentina — «disponibilidad de materias primas nacionales baratas» $\mathrm{y}$ «habilidad artesanal»- presentaba gran importancia cualitativa para proporcionar divisas. Puntualmente, sostenía que la industrialización de productos agropecuarios contaba con amplias perspectivas de convertir a Argentina en la ""granja de América Latina" (y en cierta medida de Europa y América del Norte, además de los nuevos y viejos países que se incorporan ahora al desarrollo)». ${ }^{93}$ Además, destacaba la importancia de la ALALC para la búsqueda de mercados, «sobre todo en artículos de amplia demanda en el sector de máquinas y equipos», para los cuales Argentina tenía la ventaja de ser «el país de más alto nivel de industrialización en la zona». ${ }^{94}$ No es casual que, al tratar en el último informe el caso de la rama siderúrgica, a la que consideraba de más alta prioridad, Makler apelara a una política «constante de colocación en el exterior en forma de crear mercados complementarios [...] especialmente en la zona de ALALC». El sector público debía impulsar las exportaciones siderúrgicas «en los momentos de baja y, atendiendo al principio de mantener la plena producción vital para esta industria», llegar a subsidiarlas si fuese necesario. ${ }^{95}$ Como se advierte, aunque contempladas, las ex-

91. CFI-IIEF/CGE (1963b, pp. CXXXVII-CXXXVIII).

92. Ibid. (p. CXLI).

93. Para 1962, el propio Rogelio Frigerio reconocía que se debían «incrementar e iniciar exportaciones no tradicionales a todo el mundo, y exportaciones tradicionales a nuevos destinos»y, al igual que Makler, apelaba a la industrialización de producción agropecuaria (Rougier y Odisio, 2017, p. 232).

94. CFI-IIEF/CGE (1964a, pp. 244-245, 246, 264).

95. CFI-IIEF/CGE (1965b, pp. 129-130). 
portaciones siderúrgicas estaban subordinadas a la necesidad de integrar esa industria, de un modo próximo al argumento de la complementariedad.

Sin embargo, el tratamiento que ofrecía Makler respecto a las exportaciones manufactureras se acercaba principalmente a la variante del CEI de resonancias bungeanas, cuyo núcleo eran las ventajas comparativas. ${ }^{96}$ Pero a diferencia de los planteamientos de Panorama de la Economía Argentina, la importancia cualitativa de las exportaciones manufactureras aparecía en sus aportes al Programa Conjunto matizada en vistas de «una justa ubicación de su importancia cuantitativa en el conjunto de la producción industrial», que indicaba, como se dijo, que el incremento que debían registrar para sostener una tasa anual de crecimiento sectorial satisfactoria no era racionalmente esperable a corto plazo. ${ }^{97}$ Ahora bien, pese a que entre los trabajos analizados los de Makler eran claramente los menos favorables a la reorientación industrial-exportadora, se reconoce en ellos que tal apuesta tenía un viso de realidad en los progresos logrados contemporáneamente y que el aporte de divisas que ofrecían le otorgaban una importancia cualitativa, allende su escasa significación cuantitativa.

\section{Conclusiones}

A lo largo de este trabajo han sido apuntadas diversas reflexiones que es menester sistematizar en relación con lo dicho en la introducción. Así, en primer lugar, puede afirmarse que los informes del Programa Conjunto CFIIIEF/CGE presentan claras resonancias de los debates que, desde fines de los años cincuenta, venían produciéndose al calor de la modernización de las ciencias económicas y que, para comienzos de los sesenta, fueron intensificados y ampliados al fragor de diversos aspectos de las coyunturas nacional e internacional: retracción de la demanda interna por la crisis de 1962-1963, autorrevisión del cepalismo clásico y creación de la ALALC y de la UNCTAD. Todos ellos aparecen contemplados en los aportes de los expertos que participaron de la iniciativa en cuestión. Más específicamente, se ha mostrado que estos diagnosticaban que el modo en que se había desplegado el proceso de industrialización hasta entonces —el sendero sustitutivo - había generado dificultades en el sector externo de la economía, que obstruían su prosecución. Esto era considerado especialmente problemático por su conjunción con

96. Los rasgos más genéricos de esta impronta aparecen en otros aportes al Programa Conjunto. Por ejemplo, en «Análisis económico sectorial» (primer informe, tomo I, parte VI; sin responsable informado), se señalaba que «la única manera de estar en condiciones de exportar» era encarando los problemas de productividad y de alto costo productivo (CFI-IIEF/ CGE, 1962, p. 388).

97. CFI-IIEF/CGE (1964a, pp. 244-245). 
el estancamiento agropecuario, en una coyuntura internacional signada por múltiples obstáculos para la expansión de las exportaciones tradicionales argentinas. En esa línea, el avance de las exportaciones manufactureras, como vía para la diversificación de la estructura del comercio exterior, apareció como una necesidad ineludible, aunque con grados de relevancia heterogéneos respecto a su inserción en la estrategia de desarrollo.

En segundo lugar, debe apuntarse que el análisis presentado da cuenta de que, para los expertos que colaboraron con el Programa Conjunto, el camino para ese avance no estaba allanado, pues el proteccionismo que había impulsado el proceso sustitutivo había delineado una estructura de costos que tornaba internacionalmente poco competitiva a la industria argentina. En ese punto, las propuestas de aquellos se bifurcaban, emparentándose con las diversas variantes pioneras del emergente CEI. En relación con ello, vale recordar que los expertos que abonaban esas problematizaciones colaboraron activamente con esta iniciativa mancomunada del CFI y del IIEF/CGE. Así, algunos expertos argumentaban que la competitividad internacional podía lograrse en ramas protagónicas de la integración manufacturera, pues la ALALC posibilitaba las condiciones de escala que estas necesitaban para desplegarse eficientemente y, además, brindaba la posibilidad de generar las divisas exigidas para su desarrollo. En cambio, otros sostenían que la competitividad debía basarse en el aprovechamiento de las ventajas comparativas de la industria local, para lo cual la ALALC ofrecía una interesante plataforma de demanda. Así, mientras que los primeros se acercaban al argumento de la complementariedad, tal como venían articulándolo, al menos desde 1958, Ferrer y otros expertos vinculados a la red de la CEPAL, los segundos se aproximaban a los planteos de Moyano Llerena y de la revista Panorama de la Economía Argentina. Sin embargo, esto último debe ser relativizado, pues Makler, cuya propuesta era la que más se emparentaba con el argumento de las ventajas comparativas, desconfiaba del aporte de las exportaciones industriales, enfatizando en la necesidad de apuntalar prioritariamente la integración manufacturera y su orientación mercadointernista. Cabe añadir que otros puntos aparecen de un modo transversal en los trabajos del Programa analizados. Especialmente, las posibilidades brindadas por la integración regional y por la intensificación comercial con otras áreas geográficas, las cuales habían sido bendecidas por la autorrevisión cepalina que Prebisch consagró en 1963 y que constituye una referencia constante de aquellos.

En suma, puede sostenerse que el Programa Conjunto, en tanto iniciativa surgida en la intersección entre el despliegue planificador y el interés de las corporaciones empresarias en la modernización de las ciencias económicas, representó una plataforma estatal propicia para la institucionalización de la puesta en debate de las dos modulaciones pioneras en que los noveles economistas profesionales venían problematizando la cuestión industrial desde fi- 
nes de los años cincuenta, y cuyo rasgo general - la necesidad de avanzar hacia un esquema industrial-exportador - no tardaría en dominar los debates sobre estrategias de desarrollo. En otras palabras, es posible afirmar que las bases de la reforma del desarrollo argentino, que durante la segunda mitad de los años sesenta comenzaría a desplazarse hacia un modelo mixto, aparecieron tempranamente contempladas en el seno de uno de los organismos que alimentaron el despliegue del planeamiento.

En términos más generales, estas conclusiones aportan a un proceso más amplio de renovación historiográfica que, desde la puesta en crisis del modelo neoliberal, ha complejizado las visiones sobre el pasado industrial argentino. En esa dirección, resulta evidente que aquellas interpretaciones que han advertido la consecución de un modelo de desarrollo centrado solo en el mercado interno (en especial las de cuño neoclásico) no contemplan las preocupaciones de actores fundamentales de los debates acaecidos a partir de fines de los años cincuenta, tales como los organismos de planificación y ciertas corporaciones empresariales. Como se ha mostrado, en particular para el caso del CFI y del IIEF/CGE, esos actores hicieron aportes sustantivos a tales controversias. Y aunque no haya sido el eje de este trabajo, debe dejarse apuntado que esos aportes coincidieron con el sentido industrial-exportador que más temprano que tarde asumiría la política económica. Esta vinculación abre una rica línea de investigación que puede dar profusos resultados en el futuro.

\section{Bibliografía}

Berrotarán, Patricia (2003). Del plan a la planificación. El estado durante la época peronista. Imago Mundi, Buenos Aires.

Brennan, James ; Rougier, Marcelo (2013). Perón y la burguesía argentina. El proyecto de un capitalismo nacional y sus límites (1946-1976). Lenguaje Claro, Carapachay.

CEPAL (1958). El desarrollo económico de la Argentina. I. Los problemas y perspectivas del crecimiento económico argentino. ONU, México.

CFI-IIEF/CGE (1962). Programa Conjunto para el Desarrollo Agropecuario e Industrial. 1er. informe (semestre 15-5-62 al 15-11-62). Tomo I. CFI-IIEF/CGE, Buenos Aires.

CFI-IIEF/CGE (1963a). Programa Conjunto para el Desarrollo Agropecuario e Industrial. 2do. informe (semestre 15-11-62 al 15-5-63). Tomo I. CFI-IIEF/CGE, Buenos Aires.

CFI-IIEF/CGE (1963b). Programa Conjunto para el Desarrollo Agropecuario e Industrial. 2do. informe (semestre 15-11-62 al 15-5-63). Tomo II. CFI-IIEF/CGE, Buenos Aires.

CFI-IIEF/CGE (1964a). Programa Conjunto para el Desarrollo Agropecuario e Industrial. 3er. informe ( semestre 15-5-63 al 15-11-63). Tomo I-Sección A. CFI-IIEF/CGE, Buenos Aires. 
CFI-IIEF/CGE (1964b). Programa Conjunto para el Desarrollo Agropecuario e Industrial. 3er. informe (semestre 15-5-63 al 15-11-63). Tomo I-Sección B. CFI-IIEF/CGE, Buenos Aires

CFI-IIEF/CGE (1965a). Programa Conjunto para el Desarrollo Agropecuario e Industrial. 4to. Informe. Tomo I. CFI-IIEF/CGE, Buenos Aires.

CFI-IIEF/CGE (1965b). Programa Conjunto para el Desarrollo Agropecuario e Industrial. 4to. Informe. Tomo II. CFI-IIEF/CGE, Buenos Aires.

CotTely, Esteban (1959). «La economía. Situación y perspectivas. Necesidad de exportar». Boletín Informativo Techint, 104, pp. 14-24.

Devés VAldÉs, Eduardo (2003). El pensamiento latinoamericano en el siglo XX. Tomo II: Desde la CEPAL al neoliberalismo (1950-1990). Biblos-CIDBA, Buenos Aires.

Dornbusch, Rudigern EDWARDS, Sebastián (eds.) (1992). Macroeconomía del populismo en América Latina. FCE, México.

FAJNZYLBER, Fernando (1983). La industrialización trunca de América Latina. Nueva Imagen-CET, México.

FERnÁNDEZ LóPEZ, Manuel (2001). «La ciencia económica argentina en el siglo XX». Estudios Económicos 38, pp. 1-30.

FERRER, Aldo (1963). La economía argentina. Las etapas de su desarrollo y problemas actuales. FCE, México.

- (1970). "El desarrollo de las industrias básicas y la sustitución de importaciones", en Brodersohn, Mario (Dir.), Estrategias de industrialización para la Argentina, Editorial del Instituto, Buenos Aires, pp. 475-495.

FiszBein, Martín (2010). «Instituciones e ideas en desarrollo: la planificación económica en la Argentina, 1945-1975». En Rougier, M. (comp.). Estudios sobre la industria argentina 2. Lenguaje Claro, Carapachay, pp. 27-68.

Foucault, Michel (2003). Historia de la sexualidad 2: el uso de los placeres. Siglo XXI, Buenos Aires.

Gerchunoff, Pablo; Llach, Juan José (1975). «Capitalismo industrial, desarrollo asociado y distribución del ingreso entre los dos gobiernos peronistas: 1950-1972». Desarrollo Económico, 57, pp. 3-54.

Grondona, Ana (2014). Saber de la pobreza. Discursos expertos y subclases en la Argentina entre 1956 y 2006. Ediciones del CCC, Buenos Aires.

JÁuregui, Aníbal (2014). «La planificación en la Argentina del desarrollo (1955-1973)». Temas de historia argentina y americana, 22, pp. 135-153.

Mallon, Richard; Sourrouille, Juan (1973). La política económica en una sociedad conflictiva. El caso argentino. Amorrortu, Buenos Aires.

Neiburg, Federico; Plotkin, Mariano (2004). «Los economistas. El Instituto Torcuato Di Tella y las nuevas elites estatales en los años sesenta». En NeIBURG, Federico; Plotkin, Mariano (comps.). Intelectuales y expertos. La constitución del conocimiento social en la Argentina. Paidós, Buenos Aires pp. 231-264. 
OCAMPo, José Antonio (2004). «La América Latina y la economía mundial en el largo siglo XX». El Trimestre Económico, 284(4), pp. 725-786.

Prebisch, Raúl (1963). Hacia una dinámica del desarrollo latinoamericano. FCE, México.

Rougier, Marcelo (2004). Industria, finanzas e instituciones en la Argentina. La experiencia del Banco Nacional de Desarrollo, 1967-1976. UNQui, Bernal.

- (comp.) (2016). Estudios sobre la industria en América Latina. Interpretaciones y debates. Lenguaje Claro, Carapachay.

Rougier, Marcelo; Odisio, Juan (2017). «Argentina será industrial o no cumplirá sus destinos. Las ideas sobre el desarrollo nacional (1914-1980)». Imago Mundi, Buenos Aires.

SEOAne, María (1998). El burgués maldito. La historia secreta de José Ber Gelbard. Planeta, Buenos Aires.

Sikkink, Kathryn (1988). «The Influence of Raul Prebisch on Economic Policy-Making in Argentina, 1950-1962». Latin American Research Review, 23, pp. 91-114.

Thorp, Rosemary (1998). Progreso, pobreza y exclusión. Una historia económica de América Latina en el siglo $X X$. BID-UE, Washington. 


\section{Revisiting the Argentine industrial past. The arguments on development strategies in the Programa Conjunto para el Desarrollo Agropecuario e Indus- trial (1962-1965)}

\section{ABSTRACT}

This article studies the Programa Conjunto para el Desarrollo Agropecuario e Industrial (1962-1965), promoted by the Consejo Federal de Inversiones - a government agency linked to planning - and the Confederación General Económica - an employer association of the national bourgeoisie. Specifically, it analyzes the link between this initiative and the expert problematizations that had been taking shape since the end of the 1950s in favor of an industrial-export reorientation of the Argentine economy. To do this, it describes the different aspects of these arguments and highlights the role played in its configuration by the driving forces of the program. As shown, these organizations officiated as favorable environments for the institutionalization of such problematizations. Thus, the conclusions of the article contribute to a better understanding of the displacement that the Argentine development model began to experience during the 1960s, which was in a direction coinciding with the balance of the controversies analyzed.

KEYWORDS: Argentina, industrial policy, development strategies, institutions

JEL CODES: B20, N66, O14, O25

Revisitando el pasado industrial argentino. Los debates sobre estrategias de desarrollo en el Programa Conjunto para el Desarrollo Agropecuario e Industrial (1962-1965)

\section{RESUMEN}

El artículo estudia el caso del "Programa Conjunto para el Desarrollo Agropecuario e Industrial" (1962-1965), impulsado por el Consejo Federal de Inversiones —organismo estatal ligado al planeamiento - y la Confederación General Económica —entidad patronal vinculada a la burguesía nacional- Específicamente, analiza el vínculo entre esa iniciativa y las problematizaciones expertas que desde fines de los años cincuenta venían configurándose en favor de una reorientación industrial-exportadora de la economía argentina. Para ello, describe las distintas aristas de esos debates, al tiempo que destaca el papel jugado por los actores impulsores del Programa en la configuración de aquellas. Según se muestra, esos organismos oficiaron como ámbitos propicios para la institucionalización de tales problematizaciones. Así, las conclusiones del trabajo aportan a una mejor comprensión del desplazamiento que comenzó a experimentar el modelo de desarrollo argentino durante los años sesenta, que fue en una dirección coincidente con el saldo de las controversias analizadas.

PAlabras Claves: Argentina, política industrial, estrategias de desarrollo, instituciones

Códigos JEL: B20, N66, O14, O25 